\title{
THE DEVELOPMENT TRENDS AND FEATURES OF ONLINE NEWS WEBSITES IN BANGLADESH
}

\author{
Abdul Kabil Khan \\ Department of Media Studies and Journalism \\ University of Liberal Arts Bangladesh \\ House 56, Rd, 4/A Satmasjid Road, Dhaka, Bangladesh, 1209 \\ abdul.kabil@ulab.edu.bd \\ Anna Shnaider \\ Department of Tourism \& Hospitality Management \\ Baltic International Academy \\ 4 Lomonosova str., Riga, Latvia, LV-1003 \\ anshnaider@gmail.com
}

\begin{abstract}
This article refers to the brief history of the development of online media in Bangladesh starting from the beginnings of the Internet to the contemporary stage.

Since 2006 Bangladeshi news organizations have been reshaping their strategy towards being a digital-only news outlet. News organizations are now using different features of mobile devices and social media to tell stories and engage with their target audiences. Today both the digital-only news outlets and mainstream media use QR codes, messengers, social media platforms, which enable them to reach a wider area of audiences. By using yet inexpensive digital tools journalists can easily create and distribute content for digital-only platforms.

We consider digital-only platforms as new media, social media, and convergence media platforms. Social media platforms have provided the opportunity for traditional journalists to share news quickly, get feedback from the audience, and have two-way communication with the reader.

Previous studies have looked at the genres of online journalism from a western perspective. Little has been done on the topic from the context of Bangladesh.

In this article, we analyze the basic features of online news media that exist in contemporary Bangladesh and provide an account of the development trends. We outline the new genres, techniques, and use as a sample two most famous online news platforms: The Daily Star and bdnews24. A series of semi-structured interviews were conducted with 5 different professionals from Journalism and mass media. This study is based on both primary and secondary sources of qualitative data to understand the new genres of online news media, challenges, and opportunities to work in the ever-changing media landscape.

Keywords: new media, digital media, technologies, Bangladesh, online newspapers, social media, online media, Prothom-Alo, The Daily Star, bdnews 24.
\end{abstract}

DOI: $10.21303 / 2504-5571.2021 .001858$

\section{Introduction}

The era of traditional media has passed and we are now in the age of "digital" media, which is commonly known as "new media". New media technologies have created cross-media platforms that allow journalists to collaborate in preparing stories and materials for various media. Today, the same content is distributed across multiple platforms: newspapers and magazines, websites, mobile apps, messengers, social media. The technology has a specific angle to use in the field of journalism. What everyone in journalism needs to understand about the technology from collecting information, processing, editing and distributing is made possible by the Internet, web, and mobile technologies [1].

According to Fahmidul Haq, new technology has always influenced and sometimes brought changes to the mode of production and patterns of journalism [2]. Journalism has always been shaped by technology [3]. A determinist view may prioritise technology, such as platforms and devices, over the user experience or the need to produce high-quality content that follows journalism traditions. The reality is we must consider how people consume, share and interact with media in their day-to-day lives [4]. Researchers mentioned the fourth kind of journalism, online journalism, 
which differs in its characteristics from traditional types early back in 1999. [5] Earlier, in 1996, Dahlgren, mentioned: "The advent of cyberspace will inevitably impact on the factors which shape how journalism gets done - and may well even colour how we define what journalism is" [6]. So what is the effect of Internet and digital technology on mass media? It occurs at least in 3 categories: the dynamics of news and information generation, the professional practices and skills that are necessary to survive and prosper in the new environment, and the situation of traditional media [7].

Bangladesh, a country in South Asia, which is one of the most densely populated countries in the world having more than 160 million people. The number of Internet users continues to grow here and people are becoming more interested in visualization and interactivity. In recent years, Bangladesh has seen a phenomenal increase in Internet use. According to the BTRC, the total number of Mobile Phone subscribers has reached 171.854 Million at the end of January, 2021. About $97 \%$ of the total number of Internet users in Bangladesh use mobile devices to access the network, as confirmed by a recent survey, conducted by the government. According to the BTRC, 103.191 million users have access to the mobile Internet [8].

Today news consumers move frictionlessly between different platforms for daily news at different times of the day. Many local Bangladeshi media companies are adopting digital-first approach, making content for website, mobile and social media. Users prefer accessing media content on-demand. The assistant professor from the media studies and journalism department of the University of Liberal Arts Bangladesh Dr. Sarkar Barbaq Quarmal says:

"Like other parts of the globe, increased and easier Internet access has made a significant change in the Bangladeshi media landscape; all media outlets are moving towards digitalization. All major newspapers have online news portals and maintain Facebook and Twitter pages; TV channels follow a similar trend and stream live through YouTube channels and/or their own websites. Even many newspapers published from small towns have online news portals" [9].

All these processes of transformation of the media sphere are affecting further development of the Internet media. Traditional media, such as radio, newspapers, and even television, are becoming less popular, and opposite new media platforms are becoming more multifunctional. In a competitive market, traditional media is forced to use integration in their work, an unification of at least two platforms - print and Internet version, or produce the content only for digital platforms [10].

According to P. J. Voszkowski, in the context of digital journalism, the organization of the work of media editorial offices has changed a lot. The world's major online media have created so-called "converged newsrooms", which has allowed media workers to quickly create journalistic material simultaneously for different platforms. Unlike traditional media, online journalism has a non-linear approach to news. All these features change the functions of not only the journalists but also consumers of information. Today, the production of news materials in a number of cases has gone out of the control of professional journalists. At the same time, after reading the materials on the sites, the users of the Internet media are able to publish their opinions in real-time and also have the opportunity to prepare information materials for the media [11].

Political stability in Bangladesh contributed to the development of various types of media, like online shopping platforms, new media news websites and other government platforms for citizens. The state today considers information and communication technologies (ICT) as key factors in the country's socio-economic development.

After the Awami League, the current ruling party came to power in 2008, the government was faced with the task of putting Bangladesh among the countries with an average standard of living by 2021 and significantly reducing poverty. An "electronic government" was created with the aim of using and introducing modern information technologies, wide access for residents and regional authorities to receive public services, which stimulates the country's social and economic development. Information centers of "electronic government" have been created in all regions, where residents can receive electronic services they need at their place of residence free of charge. The government pays special attention to the Digital Bangladesh program, which provided an opportunity for state and commercial structures, educational institutions, scientists, and everyone interested in owning information, to make maximum use of modern technologies in their professional activities, which will ultimately contribute to improving the daily life of the population country. 
The most important event in the development of information technology was the adoption of the "Information and Communication Technologies 2009" law [12] by the Parliament of Bangladesh, which clearly defines the basic principles of the digital state in Bangladesh.

Since 2012, the Government of Bangladesh annually organizes in Dhaka international conferences "Digital World", where the main attention is paid to the introduction of technology and knowledge, focused on economic growth, both in Bangladesh and other Asian countries.

All this today has a great impact on various spheres of the country's life, and also gives a new impetus to the development of modern journalism and the production of digital media products by Bangladeshi news media.

Online media in Bangladesh has a relatively short history. In our opinion, progress in the field of online journalism is more dependent on the development of Internet technologies in general. Internet media have already managed to overcome difficult times on their way, now they are developing successfully. Today we see that even hyper local online news portals offer multimedia content for all kinds of digital platforms. To get a complete picture of the development of Internet media in our country, we will highlight a number of periods.

The word "genre" comes from the French word genre, which means "type or class." In different sciences, genres are defined in their own way. Genre is a form of organization of one or another material for solving a specific creative task and includes all types of creativity (i.e. music, literature, cinema, journalism, etc.) According to academic D. S. Likhachev, "genres do not live independently of each other, but constitute a certain system that changes historically" [13].

Genres as categories of texts in the print media have long been studied, but the study of genres in the field of online media requires more attention. They require consideration, both from the point of view of the text, and in the interaction of information technologies when creating media content. In recent years, genres have been determined by how messages are formed for distribution using new information technologies.

Despite the unlimited volume, there is a limitation on the monitor screen, because of which it is necessary to scroll a large text many times in order to read it to the end. Therefore, the texts in the Internet media are quite compressed and in their nature are close to the genre of an extended note or report.

In Bangladesh there is the use of different genres in online newspapers. Creating a converged edition today allows you to post text messages live in real time on the Internet. Of course, all these new features have widely influenced the genre structure of the media. However, in the development of Internet newspapers, the study of genres did not receive significant attention among researchers in Bangladesh. After studying the published materials of modern Bangladeshi Internet newspapers, we noted the presence of various classic and multimedia genres. Some of them are discussed below.

\section{Materials and Methods}

This study is based on both primary and secondary sources of qualitative data to understand the new genres of online news media, challenges, and opportunities to work in the ever-changing media landscape. A series of semi-structured interviews were conducted with different professionals from Journalism and mass media. The Qualitative data was collected from semi-structured interviews with journalists, media managers, and university faculty. Based on the purposive sampling, Daily Star and Bdnews24.com newspapers were selected for the study to see the features in their websites. Several types of research-related materials were reviewed to understand the development trends of genres and features of online journalism in the global and Bangladesh context and analyze them where the question of immersive digital journalism was raised.

\section{Result and Discussion}

The period of computer Internet networks (1996-2000)

Bangladesh joined the Internet on June 6, 1996, and in 1999 received the official.bd don main, which is under the legal protection of the Ministry of Postal and Telecommunications of Bangladesh [14]. Following the domain acquisition, Banglanet, the internet segment of the Bengali 
Language, was created. In the early years, the spread of the Internet was limited by deficiencies in the regulatory framework and in infrastructure. So far, the main obstacle to using the Internet in Bangladesh is traffic distribution.

The print edition of Daily Star is considered one of the first newspapers in the country to create an Internet version. The website began work in 1997. For the first few years, the website only provided information in a static format, which was simply an electronic version of the print edition. During this period (1998-2000), many media representatives did not have their own websites [15]. At that time, the Internet was not yet considered a means of disseminating media. Instead, people mostly used the Internet to send emails. However, there were attempts to create several media projects. The number of Internet users at that time was no more than 500 people [16]. There was virtually no online advertising.

\section{The development of Internet websites (2001-2004)}

From 2001-2004, the government took several measures to ensure that the Internet was rapidly spreading throughout the country. When private Internet providers appeared in the country and a gradual increase in the number of Internet users began. According to BTRC, in 2005 there were 180 registered Internet providers in Bangladesh [16].

In the early 2000 s, dozens of national print newspapers and magazines switched to digital format, and electronic media sites emerged. These sites hosted the original content of the printed versions. At that time, there was no single concept for creating Internet newspapers. The sites of television and radio companies had not yet broadcast on the Internet in real time. Websites were only created for the government, ministries, state institutions and other authorities.

\section{The development of Internet websites (2005-2011)}

The years 2005-2011 are characterized by an increase in Internet access at low prices and new investment in Internet projects. Corporate media holdings were created. Considerable media revenue resulted from a steady growth in the Internet advertising market. At the same time, there was a dynamic development in the field of Internet media. Due to the great interest of the audience in obtaining timely information, all traditional media began to update sites as news became available in real time. During this time, the first Bangladesh blog was published to the Internet, showing the changing dynamic in Internet media and the desire for media other than news. However, most of the Internet during this time was still taken up by news [17].

Traditional media switched to digital format, changing the design of sites. Considering the audience's interest in visualization on the Internet, many online media present multimedia content to users. Many information websites publish news not only in traditional text and photo formats, but also in the form of audio, video and infographics. Started broadcasting Internet television, working on a video on demand system (Video on Demand - VoD). Television and radio began to broadcast live on the Internet. Traditional media first began using SMS portals to deliver news. In 2008, the first Internet radio station, Radio 2fun, appeared. With the growing interest of the audience, specialized online newspapers appeared on the network. Sites started posting news 24/7. On October 23, 2006, the first Internet newspaper, Bdnews24.com, premiered in the country, which today occupies a leading position in the field of Internet news media, and provides various content on digital platforms.

Following the creation of Bdnews24.com, another major multimedia news portal entitled Banglanews24.com was developed on July 1, 2010. In large cities, local online newspapers had become very popular among local readers. Internet users had begun to actively discuss social and political events on blogs. In 2005, the country created the first domestic blog platform, "Somewherein". The advent of the Bengali blogosphere was a significant event in the domestic information space.

The social media and mobile applications period (2012 to present time)

As we already mentioned that, the number of internet users in Bangladesh has continued to grow rapidly. This increase was due to the number of mobile subscribers, accessing the Internet via 
smartphones. As a result of this movement to smartphones, leading media representatives switched to mobile platforms. The use of mobile applications on various operating platforms, mobile version (WAP) sites for the distribution and delivery of news has begun. In Bangladesh, print and electronic media produce content for various new media platforms, including: websites, mobile versions, e-paper, applications for smartphones and tablets, social media and instant messaging apps.

Explaining the impact of new media in journalism, Unus Raju, senior joint news editor of Bangladesh TV channel Jamuna TV, says: "In today's media ecosystem, social media allows us to engage in a living, breathing conversation with the viewers all day long. I think the bar is much higher for what viewers will be interested in online. They don't want a report they have already seen on television. There is an expectation we will deliver something they didn't see or something with added value, and rightly so. It provides us with an opportunity to take the audience along on the journey".

The present time is described as the era of social media. Bangladesh first started using Skype as a new technology for communication with the correspondent to receive live comments. Additionally, the past five years, the social network audience expanded significantly. Media editions use the web 2.0 format to distribute various content (text, audio, and video). "Citizen journalism" is now a buzz word here in Bangladesh. Amateur photos and videos, appearing on social networks, are used to create informational materials in the mainstream media. Traditional media has already started such integrations with social networks. Today's Bangladeshi media rely on alternative sources of information, such as blogs and social networks, as events are significant and newsworthy.

\section{Online News Media Development Trends}

We have already known that the Internet emerged in Bangladesh relatively late, first developing 1996, and the past few years, it has become more widespread. According to the Government agency Telecommunications Regulatory Commission of Bangladesh (BTRC), the total number of Internet subscribers has reached 112.713 Million at the end of January, 2021. Among young people, there is a tendency to use Internet resources as news sources and a decrease in interest in traditional media. A more literate part of the country's population shows a significant interest in the blogosphere. Leading politicians, artists, and show business representatives use various social media platforms.

According to the BTRC, the total number of Mobile Phone subscribers has reached 171.854 Million at the end of January, 2021. About $97 \%$ of the total number of Internet users in Bangladesh use mobile devices to access the network, as confirmed by a recent survey, conducted by the government. According to the BTRC, 103.191 million users have access to the mobile Internet [8].

Features of the development of Bangladeshi Internet news media result from the development of Internet communications. The popularity of Internet media has been driven by the faster distribution of news and multimedia content as opposed to the slower pace of traditional media.

In the rapidly developing information space, traditional media were forced to use new technologies to maintain their image in modern society. Many editorial boards switched to the use of computer technology in the late 80 s and early 90 s. In the late 90 s \& beginning of 2000 , all the leading newspapers created their web versions for Internet users. Most of the national daily newspapers are already available electronically [18].

The editorial boards of leading national newspapers: Prothom Alo, Ittefaq, Jugantor and New Age successfully implemented innovative technologies in the field of modern journalism and now publish digital content on their website. The popular multimedia corporate news site "Banglanews24" and the first news portal "Bdnews24" are the most popular resources in the field of online journalism in the Republic of Bangladesh and have managed to grab attention with their modern interactive content.

\section{Features of the genres of Bangladeshi Internet news outlets}

Media products can be attributed to a particular genre. In general, we understand the term "genre" as a stable type of publication, united by similar substantive and formal features. Regarding the content of most media, the concept of the genre is not particularly controversial. 


\section{The News Stream}

The most common genre that has appeared in online news media and online versions of print newspapers is the news stream. This is one of the oldest genres of periodicals, telling users the latest news update. As a rule, news is for informational purposes and contains up-to-date and current information about events in the country and abroad. The news is drawn up in a short message on the principle of the "inverted pyramid", in which the most important facts are emphasized. The task of journalists, working in this genre, is to quickly convey information to target audiences.

Sabbir Ahmed, The Lead, Mobile Journalism at Bangladesh Times describes "news stream" as one of the most popular genres in online news portals. Usually we display the latest news at the home page and place the menu tab "news" with the latest being on the top of the home page. So, readers can easily find the latest updated news there, which just happened or still happening now. That's why this genre has become the most visited page of any online news portals.

Due to the faster publication of information, this genre has gained great popularity on the Internet. After analyzing the Top news websites in Bangladesh, we can conclude that notes most often appear in online newspapers. So, the websites prothomalo.com, somoynews.tv, Jagonews 24. com, kalerkantho.com, bdnews24.com, banglanews24.com, always promptly publish news stories that answer at least five key questions: What?; Who?; Where?; When; and How?

For example, on March 17, 2021, A United Arab Emirates national was found dead at a hotel in Chhatogram. Within a couple of hours, this news appeared on maximum online news sites in the form of news stories. As time passed, news was supplemented with images and video clips. Each published informational material was accompanied by a lead [19].

The lead is the first paragraph that contains the most important text information. This is a modern structure of the news text of online news media that came to Bangladesh from the West. On websites, headings and first paragraphs are placed on the main page to attract the attention of the reader. As a rule, most readers are limited to reading the lead, only if the reading has aroused the interest of the reader, he or she gets acquainted with the details of the text.

\section{The interview}

Interviews are of particular importance and are popular both in print and online news media. In modern news media, interviews are one of the most popular genres.

In Bangladesh, newspaper websites often include interview sections. Usually this is an interview with famous people from media, politics, science, economics, or sports. It is worth noting, that an analytical interview most often appears on the sites with a traditionally printed counterpart. For example, in the electronic version of the printed newspaper Prthom Alo, there is a separate section entitled "Interviews", available to users on the site www.prothomalo.com/opinion/interview. A similar section can also be found on the portals bdnews 24 and somoynews.tv at the addresses www. opinion.bdnews24.com/bangla/archives/category/interview and here: https://bit.ly/3uO22WX. These websites regularly post on the topic of events that have recently resonated in society. Today, many editorial offices have the opportunity to publish interviews, not only in text, but also in video and audio format.

\section{Web package}

The web package is one of the classic informational genres of online journalism, covering an event with multiple elements that takes place directly in the presence of a journalist. The word "in-depth reporting" is often used as a journalistic jargon while preparing this particular assignment. Unlike other information genres, the web package not only tells text stories, but gives the reader a complete picture of the events with photos, videos and audios. Mahmood Menon Khan, the Editor and Co-founder of Aparajeo Bangla, puts his emphasis:

The main purpose of a web package is to provide information in various formats. The basic point of such genres is to engage the audience with interactive multimedia content to make it work. The more multimedia elements we include, the more readers we can connect with us.

Since journalists need a fairly large amount of time to prepare a report, receiving and disseminating information is considered to be one of the basic principles of the work of modern online 
newspapers. This genre is used to cover various newsworthy events. Typically, the national issues and public interest are quite common subjects for making web package stories. Such storytelling format could be found on almost all news portals in Bangladesh. With more words and multimedia elements, the reporter may think more carefully about the possible ways to organize the web stories to keep the readers interest and attention for a long time period.

\section{The opinion}

The opinion is another genre in Bangladeshi online news media. It has long been widely used in local print media and has taken a significant place in online newspapers too. As practice shows, opinion writers are well-known experts in different fields of knowledge. They state their point of view, opinion or express an idea, analyze current social, political, cultural, technological, sports problems or situations that, one way or another, affect society.

Therefore, the commentary or opinion genre belongs to the analytical group. Now, in almost all online newspapers, we can find a dedicated menu tab at the top of the website. In journalism, opinion is used to explain to readers the importance of the subject that has been chosen by the authors.

Among Bangladeshi online newspapers, opinion most often appears on the Bdnews24.com portal. The web resource can be considered the leader in publishing opinion pieces. In their Bengali version of the "Opinions" section https://opinion.bdnews24.com/bangla/, every day an opinion article is posted on an urgent topic that has some impact on the socio-political life of the country. The authors are specialists in various fields of knowledge. More than 100 authors are registered in the public domain on their website. They are presented by surname in the form of hyperlinks and publications, distributed under the tags: "economy", "international relations", "ecology", etc. This allows readers to easily find the material of interest to a particular author. Usually, the author sends his/her write-up to the editor by email, which after moderation appears on the newspaper page along with a photograph of the author. Opinion sections can be found in online newspapers, such as prothomalo.com, kalerkantho.com, dailystar.net, and somoynews.tv.

\section{The photo story}

Today in online journalism, a vivid example of the genre can be considered a photo story, which is a collection of illustrations on a particular topic. Typically, a photo report is presented on the newspaper's website in the form of a slide show, organized according to the classical canons of a photo report, and shows the course of events. Slideshow navigation allows viewers to view photos in a wider format and even in high resolution in full screen. In Bangladeshi online newspapers, the genre of photojournalism appeared in the early 2000s and today it can be found in both central and regional online news media. According to the former photojournalist of the Bangladeshi popular newspaper Daily Prothom Alo, Arifur Rahman, today the photo story is the most common genre of online news portals in our country. It is simply impossible to imagine a full-fledged Internet newspaper without using this genre. Every news portal has a dedicated space in their website to display photos as "photos of days" or photo galleries. There should be a dedicated space for photo content in the landing page of a news website.

This interactive genre has been displayed in different ways. For example, on the Banglanews 24. com website, in addition to the photo story, users are offered the "Photo Gallery" and "Photo from Yesterday". Prothomalo.com has a separate photo distribution page: www.prothomalo.com/photo. In this case, the photo essay is posted not only in the form of galleries, but also, they have thematic sections: "Bangladesh", "Fashion", "sports", "entertainment", "international" \& "science \& technology". They also publish "photo glance", where they upload various photos. This is one of the examples of rich media in terms of publishing photo elements in a news website. About 15 to 20 photographs of various subjects are exposed daily on their special photo section "photo glance". Most of the photos come to the editors from their own photojournalists, working in different cities or rural areas of the country.

Video

Video is now considered a dominating media element on web platforms. Media publishers were discovering that visuals, including GIFs, had a major role to play in optimising the perfor- 
mance of updates on social media. Journalists now have their job responsibility to gather and publish images and videos in their text stories. They also should provide social media updates wherever possible [20].

The author of Mobile \& Social Media Journalism Anthony Adornato has described that today's journalist must have a "digital-first mindset". They can produce video content following an easy mobile journalism work-flow. Audiences are now consuming more videos than ever before. Digital-first means mobile and social media first. A digital-first approach requires journalists to use mobile devices to share and engage with audiences on social media prior to publishing on other platforms, such as websites [21].

Even back in 2014 the use of multimedia was limited on all Bangladeshi news sites because of the slow internet speeds that limit video streaming. Then many leading online news portals weren't able to run their own audio-visual units [2]. In 2014 when the country's most influential newspaper Prothom Alo started producing video content for their digital platforms, in addition to creating their own video clips, they outsourced from partner local television channels or world news agencies. After a couple of years, the news outlet established their own video department, recruiting new video editors and videographers. In July, 2016, a total of 27 journalists from Prothom Alo undertook a three-day mobile journalism workshop where they were taught basic skills of shooting, editing and publishing contents with a smartphone. It was the first time that a mobile journalism workshop was held in Bangladesh [22]. Gradually the newspaper organized such workshops across the country, building the largest mobile journalism network in Bangladesh and their journalists are now capable of shooting, editing and publishing video content straight from their smartphones [23].

In Bangladesh, today we have observed the fastest development and emphasis on the visual content due to the many technological advancements for creating and distribution of visual content. The web video is currently well represented in a number of online news portals and in some online versions of print \& electronic media. By the number of materials and the rating of views, the following can be distinguished: Prothomalo.com, Bdnews24.com, somoynews.tv, Bdnews24.com and Dhakapost.com. The video clips are posted on the main pages and repeated on others.

A web video can serve as a supporting news element with the text news story. This is a kind of small fragment of news video material. The duration of the web news video is usually short from 60 to 120 seconds; most often these are video clips, shot on a mobile camera by a correspondent or a citizen journalist.

The analysis of news websites shows that video content in online news portals along with text appear depending on the importance of the material. On the website pages of newspapers, a video piece is added, mostly prepared by their own video unit. For example, on August 4, 2014, at about 11 am local time, the Pinak- 6 ferry sank with 350 passengers on board the Padma River. As a result, more than 200 people were missing. Due to the limited access to the crash website (remoteness from large settlements, poor roads, weather conditions), journalists could not quickly reach it, and therefore the first few hours of the Internet newspaper covered this news only in the form of texts. After about 6 hours, an exclusive video footage from the scene appeared on the website of the Bdnews24.com news portal, shot on an eyewitness phone during the accident. After some time, the video clip was posted by other newspaper sites and aired on national television channels [24].

In our opinion, this is a kind of unique example of using video content in online news media in Bangladesh.

In Bangladesh, most of the news websites use Youtube as a primary channel to store and distribute video content. Bdnews24.com created their own video players based on the program Adobe Flash Player. At least 2-3 new videos appear on the tube.bdnews24.com portal every day. Most of the news websites just use the Youtube Embed code to insert video along with the text story. While Facebook is also widely used here in terms of video distribution and consumption. Users generally watch longer format videos on Youtube. Though both of them work in different ways but have had an impact on the development of such genres. Each of the news websites has a dedicated space in the website for video presentation. We can find various types of video content in the local news websites: package video, live social video, explainer video and caption-driven digital story. 


\section{Live Blogging}

Breaking news or day-long events represents a particular approach of news, reporting that news organizations can publish in their website with text, photos \& videos. Live blogging or live updates can be "live tweet" or "Facebook post".

The Guardian's former Readers Editor Chris Elliott describes live blogging as "the trunk of the tree from which individual stories branch off". Live blogs need to be written with care and restraint, or they can appear too breathless [25].

In Bangladeshi online newspapers, live blogging is not yet widely available. Although it's not a new format for presenting information of a breaking news or day-long event in the most convenient and efficient mode. According to A.R. Safina, "live blogging or, as it is sometimes called, "online reporting" is one of the newest genres, which is a collection of short news transmitted from the scene" [26].

Typically, an online journalist uses short sentences with several characters and uses mainly verbs in the present tense. This genre does not provide a detailed description of the event. To quickly send a short message with time-code and multimedia content to the editor, the journalist can do this using SMS, MMS, e-mail, social networks, as well as instant messaging apps. The journalist uses various portable devices or they perform as backpack journalists. The live blogging starts in the website with an introduction, which establishes the background of the event, updates, which aim for variety in source and medium, an ending, which rounds up the key highlights and where readers can explore more, and above it all through an evolving bullet-point list of key events or stories from the coverage, including links to any stories, which have "branched off" from it [27].

In many Western countries, live blogging is also called Twitter reporting. To do this, reporters use the microblog site Twitter, which was launched in the USA in 2006. Twitter report is a short journalistic text, consisting of a series of messages for the microblog with a length of not more than 280 characters, which is a live broadcast from the scene [28]. The main objective of a Twitter reporter is to transmit interesting, short and most important information as quickly as possible.

In Bangladesh, the live blogging genre has so far frequently appeared on the Prothomalo. com \& Dailystar.net website. On the occasion of the 11th National Parliament election 2018, the Daily Star launched a special "live updates" on their website on December 30. The website uploaded short texts and photos on their dedicated page, highlighting the important aspects of the election [29]. Any reader could follow the event by reading short messages on the information tape.

\section{Infographics}

The modern reader prefers to quickly receive relevant information in a single journalistic piece. Therefore, today one of the main trends of contemporary news media websites is the provision of compact visualization. In addition to text and photo-video materials, web tools use various statistics, data and graphic information to help readers quickly understand complex concepts.

Information graphics, or infographics, are a combination of visual representation of information, charts, graphs or maps with standalone figures, quotes and even images [4]. These infographics convey messages faster than text alone. Infographics work where you need to show the relationship of objects and facts in time and space, demonstrate the trend and organize more information [30].

Infographics are popular due to the fact that an image, graphic, diagram or chart helps to simplify the meaning and in the most convenient and a capacious way to convey complete information on a particular topic. Like all other journalistic storytelling approaches, an infographic should not only display charts or graphs, but design with an intro, body and end.

In the Bangladeshi online newspapers, the genre "infographics" appeared relatively recently. One of the very early infographics was published in 2014. During that period infographics on various issues were published on the website of the printed English newspaper "Dhaka Tribune". One of these materials was dedicated to the topic: "How Bangladesh receives smuggled weapons from various Asian countries [31]". Journalists marked the countries on an informational geographical map and drew a route diagram for the delivery of large quantities of smuggled weapons. 
Another example of the use of this genre to represent the new state budget of the country. On this topic, large print media sites, such as Jugantor, Kalerkontho, Ittefaq, bdnews24, and many other national newspapers online versions, published materials, containing visual data, dynamic diagrams, pie charts, and illustrative photographs, showing state budget key indicators [32].

The new English daily newspaper "The Business Standard" emphasizes visual and data-driven storytelling to help readers decipher the most complicated issues. The news portal has a separate infographic page on the menu bar. On 7 February, 2020, the newspapers's online version published an infographic story on global cases of coronavirus where they mentioned the confirmed cases alongside the country name across the planet. They used a datawrapper tool to create this visual infographic.

Visual materials, containing photo-video and graphic illustrations, not only attract new readers to the site, but increase its number of regular visitors.

\section{Longform}

Long-form or long-read is one of the most immersive storytelling formats for online news portals, which is typically a longer length article. Globally this genre was developed shortly after the arrival of iPad in 2010 and Amazon's Kindle Singles in 2011 and helped to expand the market. In 2012, the New York Times published a story on "Snow Fall: The Avalanche at Tunnel Creek", which literally showed to the world the beginning of longform journalism [33]. The story was combined with thousands of words, images, galleries, interactive maps, videos, animations and text-transitions. Around ten staff members from NYT put their efforts for six months to prepare this incredible longform story that finally boasted interactive user engagement.

In Bangladesh, the longform genre is also relatively a new storytelling format for online news portals. Not all news portals have these features in their site. The Bdnews 24 have been publishing longform stories since April 2020. Almost all of their published stories came from international news agencies. The stories did not include enough visual elements, such as timelines, flow charts, photos or videos.

The English daily "Business Standard" has managed to create a number of interesting longform stories. Their longform stories have been prepared with a wider area of topics and subjects. The portal has a customized URL on a longform page. Each of the stories opens with a cover photo, followed by the intro and body parts. For example, on 11th October 2019, the website published a story titled by "Amazing stories of our girls". The story deals with indomitable girls from across the country. Starting with a wide cover photo, the story introduces a human element, interviewing a number of marginalized girls, which we can easily connect with. The paragraphs were highlighted with bold titles and used 14 different sizes photos, making the story more interactive [34]. The aforementioned story has proved that to cover \& prepare a longform story, there should be definitely needed team-work to gather sufficient materials. A longform story must include multimedia elements, such as photos, videos, maps, timelines or infographics.

\section{Web Stories}

Web Stories, formerly known as AMP Story, developed by Google, is a visual-driven format for immersive news consumption on mobile-focused platforms. News publishers can develop Web Story for delivering breaking news and lifestyle content as snackable, visually rich, tap-through stories.

Web Stories immerse readers with their fast-loading full-screen experiences as images or videos appear in portrait mood. Publishers easily create visual narratives, with engaging animations and tappable interactions. Stories can be shared and embedded across the web without being confined to a closed ecosystem or platform [35]. There is a real opportunity for advertisers and publishers to attract target audiences, publishing advertisements on Web Stories with immersive user experiences.

CNN, Conde Nast, Hearst, Mashable, Meredith, Mic, Vox Media, and The Washington Post - have already started using this format to tell immersive stories. Greg Manifold who is the Design Director of The Washington Post has expressed Web Stories as a unique platform for fast 
and smooth publications. As a source for breaking news and information, Web Stories allow us to showcase our quality journalism when there are multiple elements we want to bring together. Combining reporting, photography, videos and motion graphics, this gives readers a more visual entry point when they are searching for our coverage [36].

Web Stories is a very new experience for Bangladeshi online news portals. The Dhaka Post online news portal became the first ever Bangladeshi online newspaper who published this feature. Since the beginning of their journey from February 16, 2021, they have already published a good number of Web Stories on entertainment, lifestyle, sports, travel, Bangladesh, international \& islam. The website has a dedicated landing page on Web Stories and displays all Web Stories according to the different themes. The maximum Web Stories were published on entertainment, lifestyle and sports sections. The feature editor Ariful Islam highlights that the website may achieve more engagement if the feature enables in the search engine from Bangladesh.

"We have a good response on this particular content. Currently we are getting more users on Web Stories from the USA \& Middle East. Still this feature is not visible on search engines from Bangladesh, but anyone can find it from abroad. Every day we try to publish at least 2-3 Web Stories and for that we need 10 photos to complete the storytelling process. Initially we are focusing more on creating feature-based Web Stories rather than hard stories and we are struggling with good quality photos. Because Web Stories need high-quality vertical images or video that fits the entire screen.

Beside Dhakapost, the one of the oldest newspapers in Bangladesh, the Ittefaq, has also launched Web Stories on their website. As like Dhakapost, the portal also has focused on lifestyle and entertainment content while producing Web Stories.

\section{Platforms of Modern Online Newspapers}

The audience of Internet users is growing rapidly. People are increasingly interested in receiving news online and on any convenient medium in audio-video and text formats. To obtain information, people use mobile applications, social media, online versions of print media and the Internet newspaper itself. The following parts will highlight the various online newspaper platforms in Bangladesh.

\section{Online version of the newspaper}

An online newspaper is one way to get quick access to information. In Bangladesh, online newspapers are poorly financed and lacking qualified personnel. Nevertheless, some online media are still quite actively visited by readers both at home and abroad. Bdnews24.com, jagonews24, banglanews 24 and other news sites operate $24 / 7$.

Television channels broadcast live news via the Internet or satellite. The most popular video clips of Bangladeshi news or entertainment channels can be found on Facebook and YouTube. The Youtube live feature is available for many national television channels. Moreover, video on demand services are more popular on Youtube rather than the live broadcast. The news channels like Somoenews, Jamuna, DBC, Independent publish short video clips just after the broadcast. In Bangladesh, users of new media regularly express their views on social media on many important national issues, politics, sports, festivals, etc. Almost all daily-printed media have their own online versions. The popularity of online news is growing significantly. According to the Alexa ranking, the country's top online newspapers are Bdnews24.com and Banglanews24.com.

On the other hand, being a print newspaper, Prothomalo.com is the most popular web destination for online news readers in Bangladesh. Prothomalo.com started its journey back in 2006 and today is the largest and most widely read Bangla language website in the world across all segments and categories. They have readers from all walks of life. The news portal has average monthly users of $12.5+$ million. On an average a user spends around 10+ Minutes daily on their website. $70 \%$ of their users are between ages of 18-34 years [37].

Bangladesh newspapers initially used hand printing, then the printing technology was modernized and switched to offset printing. Today, all publications in Bangladesh use digital technology; the computer in the newspaper industry has become the main tool on the desktop. The owners 
of leading newspapers have equipped all of their offices with computers as well as provided them to reporters. Most newspapers and periodicals have an IT department for digitizing manuscripts and technical processing. The editors of major online media use news monitoring software.

The Internet has created a self-governing environment with many interesting opportunities: online readers do not need to receive morning newspapers with news; portable devices, laptops, tablets, smartphones enable easy access to online newspapers. Users receive news and information in accordance with their interests and can save the necessary materials.

\section{Websites of online media on the mobile}

The rapid development of information and communication technologies (ICT) in Bangladesh creates new opportunities for the development of the country. Mobile Internet is a new trend in Bangladesh that is widely used by literate people. In order to become a mobile Internet user, a GPRS or EDGE connection is necessary. The main advantage of mobile Internet is the ability to use it anywhere in the country with a mobile connection.

In October 2012, the country officially launched the use of a new generation of wireless communications. Prime Minister Sheikh Khasina announced the provision of $3 \mathrm{G}$ services by the state mobile operator, Teletalk [36]. On February 19, 2018, Bangladesh entered into another new landmark of digital connectivity with the fourth-generation mobile internet. The telecom operators Grameenphone and Robi were the first to start providing 4G network services in the country [38]. The media began to create websites for mobile Internet users. A mobile site is a specialized version of a website, adapted for various mobile devices that differ in the arrangement of elements and menus from traditional portals. A mobile site will enable users to access websites that open on browsers via mobile devices.

One of the trends of online media news websites is the speed presentation of information on portable platforms for mobile Internet users. The main goal of creating these websites is to reach an audience that does not use mobile applications. The widespread use of mobile Internet in Bangladesh is promoted by the very low tariffs, provided by mobile operators.

\section{Newspapers in mobile applications}

Web applications are programs designed to be used exclusively within the browser. Using the application, users can create documents, edit photos, and listen to music without overcomplicated software. Websites are capable of dynamic functionality and enable the realization of the expectations of applications on a computer. These websites are called Mobile Applications. They are available through application stores: Apple App Store, Google Play, Windows Phone Store, BlackBerry App, etc. Applications are downloaded from the store to the device, and sometimes they can also be used on laptops or desktop computers.

According to the information technologies expert P.V. Pechkovsky, mobile applications are software products, designed to work on smartphones, tablets or other mobile devices [39]. The author believes that multifunctional and diverse mobile applications greatly facilitate the life of a modern person.

The difference between Western and Bangladeshi media is manifested, among other things, in the lag in the use of modern technologies, but Bangladeshi media are trying to improve the level and quality of news for users. The first online newspaper, Bdnews24.com, works 24/7 and is available on any media channel. Since October 23, 2006, this bilingual news website has been regarded as the most reliable source of information, being reliable and professional.

Bdnews24.com is available for iOS, Android and Facebook applications. This application works in Bengali and English, has an interactive interface and an integrated modern multimedia platform. The fast-growing online newspaper Banglanews24 was the country's first web newspaper to develop iOS apps. The popular app of the daily newspaper Prothom Alo is also available for users of iPhones, iPads, smartphones and tablets on Android and Windows platforms. Prothhom Alo and Bdnews24 mobile application users receive news alert notifications. A number of online media in Bangladesh have mobile applications, among them: Ittefaq, Daily, Kalerkantho, Bangladesh Protidin, Daily Star, etc. The mobile applications almost have the same content and news display as they have made it for the web version. 
Newspapers in social media

Most news websites in the country use various types of social media. Almost all of Bangladesh's online newspapers feature and distribute content on Facebook, the country's most popular social network. The microblog Twitter is not used as widely. Apart from Facebook, YouTube is another popular destination among audiences to watch video-on demands content. Media representatives post and store videos on YouTube and video links, embedded in the websites, to make it visible in the landing page. Instagram is another social media, which is also getting popular among the online news publishers. Prothom Alo is one of the most influential media outlets on Instagram, launched their account on 9 March 2014. The publisher has already received 5,00,000 followers and published more than 3,861 posts. They mostly use news photos to publish on the main feed.

\section{QR codes for the media}

A promising platform for the distribution of news content may be the QR codes. The word "QR" comes from the English Quick Response. This is a two-dimensional bar code, encoding a small amount of data that can be read using special smartphone applications. Matrix code is a modern way of mobile technology that allows users to quickly go to a website to get more information on a topic of interest. In many countries, QR codes are widely used to promote information for various purposes, including in media. In Bangladesh, in September 2012, the distribution of news content via QR codes was the first to be mastered by the English edition of the Daily Star.

In the printed version of the newspaper, the most important materials are accompanied by QR codes, located next to the headings. This greatly simplified the transfer of information to users. The Prothom alo print newspaper also frequently publishes QR codes for newspaper readers, offering them to watch video clips from YouTube. Currently, very few news platforms in the country implement this technology for the delivery of information resources. However, QR codes can also be found on some news sites that provide only a link to download their mobile applications.

In our opinion, in Bangladesh QR codes have not yet received sufficient popularity among Internet users. To attract their interest in the use of QR codes, the media must be informed about these features.

\section{Messengers for the media}

As a result of the convenience, speed, and multifunctional advantages, digital platforms, such as instant messaging apps, have prospects in the field of mass media not only for disseminating their content, but also as a source of user-generated content.

The word "messenger" comes from the English Instant Messenger (IM) - "quick messaging service." This is a special mobile program or web service that allows you to exchange instant messages in the form of texts and media files over the Internet in real time. Messengers synchronize between a mobile device, tablet and computer.

In Bangladesh, interest in instant messaging apps is growing rapidly. As already mentioned, the number of smartphone users is increasing rapidly, mobile operators offer attractive rates, and even there are special options for using messaging apps, such as WhatsApp or Messenger, which causes particular interest in using new digital communications services.

The Bengali daily newspaper Prothom Alo is the leader in the terms of using instant messaging platforms for the distribution of multimedia news content. Exploring the way platforms distribute content through instant messaging apps, we noted that Prothom Alo is expanding its activity on popular instant messaging apps, such as Whatsapp, Viber and Line.

\section{Results}

Features of the news websites "thedailystar.net" and "bdnews24.com"

The Daily Star was established as an English newspaper in the media landscape of Bangladesh on January 14, 1991. The Daily Star became the first ever newspaper in Bangladesh launched their news website in 1997.

While the bdnews24.com initially began their journey as a news agency and then went on to become the country's first internet newspaper in 2006. 
Both of these news portals have such a unique identity, featuring online journalism in Bangladesh. Based on the interactivity content, multimodality, and textuality on their websites, they have already achieved popularity as an electronic platform to distribute news content. Here will be explored the features of "The dailystar.net" and the Internet newspaper "Bdnews24.com" as a sample from the entire online newspapers of Bangladesh.

The Daily Star: The online version of the "Daily Star" print newspaper is the most visited English news website by Bangladeshi and foreign citizens at home and abroad and is often cited in national and international magazines, seminars, and research papers as the most reliable and trusted news source. It is a major taxpayer among the country's media.

The English-language newspaper "Daily Star" is well known as a respected media outlet in the country, as well as among young journalists and university graduates. Their print version is the highest circulated English newspaper in Bangladesh. The newspaper pays standard wages to employees who have acquired a reputation for fair and responsible journalism, popularity, and public support. They update the website $24 / 7$ with breaking, political, business, entertainment, sports, and crime news.

According to Alexa ranking, thedailystar.net ranks first among the English-language issues in Bangladesh. The news is updated on a daily basis, which makes it possible to quickly learn about current events in Bangladesh and in the world. Thedailystar.net is ranked 6,637 in the global [40]. The web page reached 27th position among the users in Bangladesh. A user spent around 4 minutes and 17 seconds on the website each day. About $70 \%$ traffic came from Bangladesh, followed by the USA \& India. The top of the home page there are 13 menu tabs and some of them have separate categories. The lead story appears with another 3 more stories at the landing page. The website also publishes Bengali news, which has turned the web as a bilingual website.

The Dailystar.net has a number of features that are mainly displayed on the home page. In 2014-15, the home page included multimedia presentations, available on podcasts, English bulletin of ATN Bangla TV, and the latest news from ABC Radio. Gradually they removed all these features from the website. Today we can only find photo galleries and video content (Star Live) as multimedia elements in the home page. Some of the basic widgets of the newspaper are sending news to email, RSS feed and social media icons. The user can send a comment on a news story using their Facebook account. Each article can be posted on Facebook and Twitter by clicking the share button on the social media logo and can also be sent to email or Messenger.

The Daily Star is positioning itself in the Bangladesh media arena as an independent source of news and information. It has mobile applications on Android, iOS, and Windows and enables users to receive content from the website on smartphones and tablets. The Daily Star is active on social media. The website publishes various posts and content on their Facebook, Twitter, Instagram, Youtube and Pinterest.

Bdnews24.com: It is one of the fastest and most reliable news sources in Bangladesh and the first online newspaper in the country. It is considered a news agency and sells material for national newspapers and TV channels. The bdnews24.com website was launched on 23 March 2006. Bdnews24.com is a modified online version of BD News, originally launched as a news agency to serve readers and the media. The portal is known as Bangladesh's largest news publisher by reach $\&$ volume where the readers can get news content both in Bangla and English. Over the years they have identified themselves as an Internet-only and global first news portal.

Bdnews24.com has a global Alexa ranking of 2,142 and ranked 9th position among all websites, visited from Bangladesh. About $37 \%$ of traffic comes from different search engines. The website has monthly 3.79 million unique visitors and daily 2, 74,00 unique visitors hit the website. A visitor spent 5 minutes and 13 seconds on the website per day. About $77 \%$ of users are from Bangladesh, followed by India, USA, Saudi Arabia, South Korea, Canada, Japan, and several other countries [41].

When the web page bdnews24.com was launched, news from the BBC, Reuters, Deutsche Welle, and Voice of America were posted on its home page. On the front page, in addition to one main story, 9-10 other news stories are posted in columns as "other top stories", which are updated in real-time as the materials are received. The lead story is also followed by another 2 important 
stories, placed just below of the main story. At the header part, a user can find all the 8 menu tabs and can explore more content, clicking the "more" tab. All the three social media icons are also visible here. The other features of the web page include RSS feed, setting it as a homepage button, blogging platform, tags, photo gallery, photo archive, bilingual version, and more. From the very beginning the portal launched a separate space for citizen journalists. The dedicated blog page blog.bdnews24.com is one of the most visited and active blog platforms for Bengali speakers. At present they have eleven thousand registered citizen journalists, and amongst which a major portion belongs from abroad, such as from Germany, France. There are also few who are not Bangladeshi citizens but know Bangla, such as from West Bengal, India.

The website publishes news content both in Bengali and English Languages. Recently, a new web page has been developed specifically for use in social media. The users can join in the opinion poll section and find the most read recent stories and most viewed stories at the right side of the middle of the web page. The site offers users various paid services for receiving news via SMS-messages to a short number, as well as "push-notifications" for delivering urgent news using mobile applications. The website is also available on Android and iOS platforms. This is how major world news agencies work today.

Technical progress, and in particular the production and dissemination of information technology, has always contributed to social progress, increased the human ability to process and preserve knowledge, and helped the development of the media industry. Other words, technology enabled journalism. The trend of technological innovation continued, and facilitated the adoption of new mediums of distribution that became ever cheaper and faster. The Internet media today acts as a modern medium. In terms of the nature of the product produced, Internet media differs from traditional media. The audience of the Internet mass media instantly receives relevant, interesting, multimedia, interactive, and regularly updated information. Journalists who work in this direction are engaged in all processes of processing information. They are responsible for multimedia content of an analytical or news nature; for the prompt dissemination of information, aimed at the target audience on the Internet in various formats 24/7.

We are witnessing the period when new types and genres of journalism are born in Bangladeshi online news portals. And technologies, provided by new media, will continue to change the relationships between the audience and mass media. We can see how journalism has changed in Bangladesh since its appearance and in the near future we will see the influence of implementation of VR, Artificial Intelligence and Machine Learning in journalism. The further research on this topic is required, finding out the readiness of the news media using AI in the newsroom.

In the past few years we have seen some significant changes of journalism worldwide and in particular in Bangladesh. As an industry news media is constantly growing and considering the ever-expanding requirements from the job seekers. Online journalism has already received huge popularity. Online new websites are publishing multimedia stories, podcasts, live reports, text news on a 24/7 cycle. The innovation around the new ways of storytelling in digital platforms has also been accelerated through the opening up of new possibilities for non-professional journalists. The blogs are now integrating with the main news platforms, informing us that we must grow our habit and mindset to digest news content from a wide variety of media platforms. More and more news establishments are making their website accessible for internet users. At the end of July 2020, the Information Ministry of Bangladesh has released a list of 34 verified media outlets as part of its process of registering online news portals. The report has mentioned that the 3,000 news portals applied for registration [42].

As technology improves constantly, mobile reporting becomes more established in today's newsrooms in Bangladesh. Mobile journalism, which we call MoJo, is an innovative form of storytelling where people use only their smartphone to create and file stories from the ground. As target audiences are becoming to have more and more savvy on social media, online, mobile devices and the Internet, the traditional form of mass media is trying out on how to integrate digital and traditional media into a framework for a successful business model. A major development in this respect has been the rise of mobile journalism in the context of 
Bangladesh, and the development is so significant that we will devote our next research on the aforementioned topic.

\section{Conclusion}

The implementation of information technologies in journalism had a huge impact on news gathering, processing, production and distribution of media content worldwide, and in particular in Bangladesh. Though we need to admit that there is an issue in implementing modern technologies, the most noticeable one is the lack of digital skills of modern journalists. That's why there are some centers and private courses where modern journalists are studying how to make a video, how to make a montage, how to make an audio, how to upload the content to the digital platforms and how to communicate with the audience on different digital platforms.

Over the last five-six years Social media has been the primary mode of news delivery and consumption for specific demographic cohorts and young netizens that are in significant part an audience of online news media. That's why it's so important for traditional newsrooms to stay updated with the new trends of gathering and distribution of the content. Modern newsrooms should pay attention to the skills of journalists and have the possibility to provide training for all the employees, so they can produce different genres and storytelling for online platforms.

Talking about the recommendations for journalists who work in Bangladesh, it's obvious that they should take an audience-centric approach. By having skills to make news in a user-friendly way, then they will get more audience. If the newsrooms will provide training programs and invest money in capacity buildings of employees, then journalists could adapt themselves with new tools and gadgets. As the main issue for media is financial part of its existence, traditional and new media that are operating in Bangladesh should find a new business model for sustainability, and for proper optimization of resources. There should be an industry approved metric system to measure the effectiveness of using digital technology in journalism. By having one it will move forward the process of adapting and implementing new technologies in online mass media that will scale up the whole mass media improvement and newsrooms could gain more profit.

There is a necessity to continue to study this topic in near future, to distinguish the credibility problems with online media, to learn the perception of the audience on online newspaper content, its preferences when consuming any kind of digital content of traditional and online news media. Starting point for considering online media should therefore be its challenge to our core assumptions about the mass media, society and its journalism.

\section{References}

[1] Rashid, M. (2018). Technology and Journalism: A Perspective on Bangladesh. Imperial Journal of Interdisciplinary Research, 4 (1), 184-193. Available at: https://www.researchgate.net/publication/335684577_Technology_and_Journalism_A_Perspective_on_Bangladesh

[2] Fahmidul, H.; Brusila, R., Vanhanen, H. (Eds.) (2014). Online Journalism in the Developing World: The Case of Bangladesh. Integrated Media in Change. Rovaniemi: Lapland University Press.

[3] Pavlik, J. V. (2001) Journalism and New Media. New York: Columbia University Press. doi: http://doi.org/10.7312/pavl11482

[4] Hill, S. Bradshaw, P. (2018). Mobile first journalism. New York: Routledge, 240. doi: http://doi.org/10.4324/9781315267210

[5] Deuze, M. (1998). The WebCommunicators: Issues in research into online journalism and journalists. First Monday, 3 (12). doi: http://doi.org/10.5210/fm.v3i12.634

[6] Dahlgren, P. (1996). Media Logic in Cyberspace: Repositioning Journalism and its Publics. Javnost - The Public, 3 (3), $59-72$. doi: http://doi.org/10.1080/13183222.1996.11008632

[7] Franco, G. (2009). The Impact of Digital Technology on Journalism and Democracy in Latin America and the Caribbean. Available at: https://www.issuelab.org/resources/9785/9785.pdf Last accessed: 20.03.2021

[8] BTRC. Mobile internet users in Bangladesh 2021. Available at: http://www.btrc.gov.bd/content/internet-subscribers-bangladesh-january-2021 Last accessed: 20.03.2021 
[9] Quarmal, S. B. (2020) Bangladesh. The SAGE International Encyclopedia of Mass Media and Society. SAGE Publications, Inc. Thousand Oaks. doi: http://doi.org/10.4135/9781483375519.n65

[10] Khan, A. K., Shnaider, A. (2020). Journalism Education in Bangladesh: Past and present. The current state of media education in Russia in the context of global trends. Taganrog.

[11] Pablo, J. (2005). Boczkowski. Digitizing the news: Innovation in Online Newspapers. Cambridge: MIT Press, $158-159$.

[12] Law ICT- 2009. Available at: http://goo.gl/4wEoBB Last accessed: 16.03.2021

[13] Kim, M. N. (2004). Zhurnalistika. Metodologiya professionalnogo tvorchestva. Saint Petersburg: Izd-vo Mihajlova V.A., 496.

[14] Trofimova, G. N. (2003). Journalism on-line: some tendencies of evolution. Vestnik Rossiiskogo universiteta druzhby narodov. Seriia «Literaturovedenie. Zhurnalistika», $10 \leqslant-1 \leqslant 0, \Lambda_{-} \vee$.

[15] Azam, S. (2007). Internet Adoption and Usage in Bangladesh. Japanese Journal of Administrative Science, 20 (1), $43-54$. doi: http://doi.org/10.5651/jaas.20.43

[16] The newspaper "Vhorer kagoj" (2014).

[17] Internet in Bangladesh. Available at: https://opennet.net/research/profiles/bangladesh

[18] Online news portal: A new plot of modern journalism in Bangladesh (2011). Zhurnalistika i Nauka. Moscow: RUDN, 7-13.

[19] UAE national found dead at hotel in Bangladesh (2021). Bdnews24.com. Available at: https://bdnews24.com/bangladesh/2021/03/17/uae-national-found-dead-at-hotel-in-bangladesh Last accessed: 17.03.2021

[20] Rogers, S. (2014). What fuels a Tweet's engagement? Twitter. Available at: https://blog.twitter.com/en_us/a/2014/what-fuels-atweets-engagement.html\#: : text=So\%2C\%20the\%20most $\% 20$ effective $\% 20$ Tweet,a $\% 2019 \% 25 \% 20$ boost $\% 20$ in $\% 20$ Retweets Last accessed: 19.03.2021

[21] Adornato, A. (2018). Mobile and Social Media Journalism. California: Routledge, 96. doi: http://doi.org/10.4135/9781506357126

[22] Khan, J. (2016). MoJo makes breakthrough in Bangladesh. Prothomalo. Available at: https://en.prothomalo.com/opinion/MoJo-makes-breakthrough-in-Bangladesh Last accessed: 19.03.2021

[23] Scott, C. (2017). Prothom Alo is building the largest mobile journalism network in Bangladesh. Journalism. Available at: https:/www.journalism.co.uk/news/prothom-alo-largest-mobile-journalism-network-in-bangladesh-/s2/a711795/ Last accessed: 19.03 .2021

[24] Witness shoots Pinak-6 sinking (2014). Bdnews24. Available at: http://bdnews24.com/bangladesh/2014/08/04/witness-shootspinak-6-sinking Last accessed: 18.03.2021

[25] Inside the Guardian: how the live blog has changed the face of news reporting (2016). The Guardian. Available at: https:// www.theguardian.com/membership/2016/feb/04/inside-the-guardian-how-live-blog-changed--ews-reporting Last accessed: 20.03 .2021

[26] Safina, A. R. (2013). Features of genres of internet mass-media. Izvestiia Samarskogo nauchnogo centra Rossiiskoi akademii nauk, 15 (2), 226-229.

[27] Bradshaw, P. (2017). The Online Journalism Handbook: Skills to survive and thrive in the digital age. Routledge, 368.

[28] Ulanova, M. A. (2014). Internet-zhurnalistika. Moscow: Aspekt Press, 41.

[29] LIVE poll updates (2018). Daily Star. Available at: https://www.thedailystar.net/bangladesh-national-election-2018/live-updates Last accessed: 20.03.2021

[30] Tuchkevich, E. I. (2014). Samouchitel’ Adobe Illustrator CS6. Saint Petersburg: BHV Peterburg, 322.

[31] Newspaper "Daka Tribune" (2014).

[32] Newspaper "Dzhugantor" (2014).

[33] Dowling, D., Vogan, T. (2014). Can We “Snowfall” This? Digital Journalism, 3 (2), 209-224. doi: http://doi.org/10.1080/2167 0811.2014.930250

[34] Amazing stories of our girls (2019). The Business Standard. Available at: https://www.tbsnews.net/women-empowerment/ girl-power Last accessed: 20.03.2021

[35] Web Stories. Amp. Available at: https:/amp.dev/about/stories/ Last accessed: 21.03.2021

[36] Prothom Alo Digital (2018). Service.prothomalo.com. Available at: https://service.prothomalo.com/palo/sales-kit-2018.pdf Last accessed: 21.03.2021

[37] Newspaper "Prothom alo" (2013). Available at: https://www.prothomalo.com/

[38] A year of 4G, controversies and satellites in space (2018). The Daily Star. Available at: https://www.thedailystar.net/bytes/ news/year-4g-controversies-and-satellites-space-1678147 Last accessed: 21.03.2021

[39] Pechkovskii, P. V. (2015). Biznes-plan startup-proekta «Health\&Beauty». Moscow: Designio Publishing Store, 45.

[40] Competitive Analysis, Marketing Mix and Traffic (2021). Alexa. Available at: https://www.alexa.com/siteinfo/thedailystar.net Last accessed: 21.03 .2021 
[41] The Impact of Technology on Journalism (2006). Matthew Sparks. Available at: https://matthewsparkes.wordpress. com/2006/02/17/the-impact-of-technology-on-journalism/ Last accessed: 20.03.2021

[42] Dhaka Tribune (2020). Available at: https://www.dhakatribune.com/bangladesh/government-affairs/2020/07/31/govt-releaseslist-of-44-verified-online-news-portals Last accessed: 20.03.2021

How to cite. Khan, A. K., Shnaider, A. (2021). The development trends and features of online news websites in Bangladesh. EUREKA: Social and Humanities, 3, 41-58. doi: http://doi.org/10.21303/2504-5571.2021.001858

\title{
ANALYSIS OF CHANGES IN THE ADMINISTRATIVE- TERRITORIAL STATUS OF MONOPROFILE CITIES OF DONBAS (LATE 1940s - 1980s)
}

\author{
Valeriy Bohunenko \\ Department of Domestic and Foreign History \\ Horlivka Institute for Foreign Languages of the State Higher Educational Institution "Donbas \\ State Pedagogical University" \\ 24 Vasylia Pershyna str., Bakhmut, Donetsk region, Ukraine, 84511 \\ bogunenkovalery@gmail.com
}

\begin{abstract}
Absract
Transformations of the administrative-territorial status of monoprofile cities of Donbas in the context of development of structural-settlement structure of the region in the late 1940s and 1980s are considered. The urgency of the study is due to the reform of decentralization in Ukraine - changes in the order of local self-government and territorial organization of power. Its goal is to create communities that are self-sufficient and effective in the economic, administrative and socio-cultural dimensions. In the course of reform, monoprofile cities often acquire the status of centers of united territorial communities. In assessing the relevance of such decisions to the purpose of the reform, it is advisable to examine the relationship of structural-settlement, socio-economic and administrative-territorial status of these cities in historical retrospect. It turns out that the monoprofile cities of the region are an industrial-urban phenomenon, the genesis of which influenced the formation of the specifics of the settlement structure of Donbas. During the study period, the number of such cities more than doubled, reaching more than sixty cities in the late 1980s. Their share among the settlements of the region with the administrative status of a city was at that time two thirds. The emergence of monoprofile cities in the region in large numbers in the 1940s - 1980s is associated with government-industrial policy. At the same time, the structural and settlement importance of these settlements was reflected in their acquisition of the administrative-territorial status of region or district cities. From the beginning of the study period, the vast majority of cities with a narrow industrial base in the region belonged to the cities of district subordination, as they did not meet high enough urban criteria. In the urbanized region, in the presence of other, more powerful urban centers, the corresponding role in the administrative-territorial organization programmed the secondary nature of their structural settlement development. In particular, it did not contribute to the formation of micro-regions around these cities, which must be taken into account in the current conditions of reforming local self-government and territorial organization in the country.
\end{abstract}

Keywords: monoprofile cities, Donbas, administrative-territorial status, settlement structure.

DOI: $10.21303 / 2504-5571.2021 .001862$

\section{Introduction}

The development of the settlement structure of urbanized regions is associated with the problem of spreading the «urban environment», its compliance with the administrative boundaries of urban settlements and their administrative status [1, p. 64-65]. Important is 